\title{
Orthostatic hypotension in older people: considerations, diagnosis and management
}

\author{
Authors: Melanie Dani, ${ }^{\mathrm{A}}$ Andreas Dirksen, ${ }^{\mathrm{B}}$ Patricia Taraborrelli, ${ }^{\mathrm{B}}$ Dimitrios Panagopolous, ${ }^{\mathrm{C}}$ Miriam Torocastro, ${ }^{\mathrm{D}}$ \\ Richard Sutton ${ }^{\mathrm{E}}$ and Phang Boon Lim $^{\mathrm{F}}$
}

Orthostatic hypotension $(\mathrm{OH})$ is very common in older people and is encountered daily in emergency departments and medical admissions units. It is associated with a higher risk of falls, fractures, dementia and death, so prompt recognition and treatment are essential. In this review article, we describe the physiology of standing (orthostasis) and the pathophysiology of orthostatic hypotension. We focus particularly on aspects pertinent to older people. We review the evidence and consensus management guidelines for all aspects of management. We also tackle the challenge of concomitant orthostatic hypotension and supine hypertension, providing a treatment overview as well as practical suggestions for management. In summary, orthostatic hypotension (and associated supine hypertension) are common, dangerous and disabling, but adherence to simple structures management strategies can result in major improvements.

KEYWORDS: orthostatic hypotension, older, supine hypertension, postural hypotension, orthostasis

DOI: 10.7861/clinmed.2020-1044

\section{Introduction}

Orthostatic hypotension $(\mathrm{OH})$ is common in older people and is encountered daily by emergency and general physicians. Defined by a drop of $>20 \mathrm{mmHg}$ in systolic blood pressure (BP) or $>10 \mathrm{mmHg}$ diastolic BP after standing for three minutes, it is seen in almost a quarter ( $24 \%$ ) of emergency department (ED) presentations with syncope, a fifth $(19 \%)$ of older trauma inpatients and $68 \%$ of older general medicine inpatients. ${ }^{1-3}$ It is a persistent problem: Hospital Episode Statistics show that

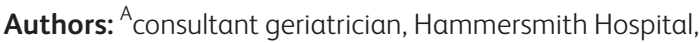
London, UK and Imperial College London, London, UK; ${ }^{B}$ clinical nurse specialist in syncope, Hammersmith Hospital, London, UK; ${ }^{C}$ clinical research fellow in cardiology, Imperial College London,

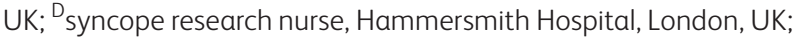
Eprofessor of clinical cardiology, Imperial College London, London, UK; ${ }^{F}$ consultant cardiologist, Hammersmith Hospital, London, UK admissions resulting from $\mathrm{OH}$ have risen dramatically over the last decade. $^{4}$

$\mathrm{OH}$ is neither incidental nor benign. It is associated with a higher risk of coronary artery disease, myocardial infarction, stroke, falls, fracture, road accidents and death. ${ }^{5-8}$ A sustained reduction in systolic BP on standing is an independent risk factor for death with a $45 \% 5$-year mortality. ${ }^{9}$ Furthermore, the diagnosis can be overlooked when patients with delayed $\mathrm{OH}$ are unaware of their reduced cerebral perfusion, reporting falls rather than dizziness or syncope.

It is thus essential that it is identified, and that the consequences are anticipated and managed. In this review article, we outline the pathophysiology of $\mathrm{OH}$, along with specific associations to consider in older people. We then detail the management principles and emerging evidence.

\section{Pathophysiology of $\mathrm{OH}$ in older people}

When a human stands up, 500-1,000 mL blood pools from the thoracic cavity to the legs, buttocks, abdomen and pelvis. Blood in the abdomen pools in the splanchnic vascular bed which can contain a quarter of the body's blood at any time (Fig 1)..$^{10-12}$

To compound this, plasma volume decreases by $10-15 \%$ as fluid from the plasma shifts into the interstitial spaces in the lower legs from osmotic forces. As a result of this redistributed plasma volume, there is lower venous return to the heart. Consequently, the pressure in the right atrium falls, right ventricular filling falls, leading to reduced stroke volume and, ultimately, lower cardiac output. $^{10-12}$

The body's response to standing (orthostasis) is finely regulated. Walking, involuntary postural sway and voluntary leg muscle contraction act as a pump (aided by venous valves) and propel significant volumes of blood towards the heart. ${ }^{10-12}$ The autonomic nervous system (ANS) also plays a role. The reduction in venous return to the heart and the subsequent fall in cardiac output is detected by the baroreceptors in the aortic arch and carotid sinus, and the venoatrial stretch receptors in the heart and lungs. On sensing the lower arterial pressure, these baroreceptors send signals to the brain to increase sympathetic outflow. This, in turn, induces peripheral vasoconstriction, splanchnic vasoconstriction and increases plasma noradrenaline release from sympathetic neurons. Consequently, the heart rate increases and, to a lesser extent, stroke volume also increases, given normal cardiac function. The renal angiotensin system is activated by 

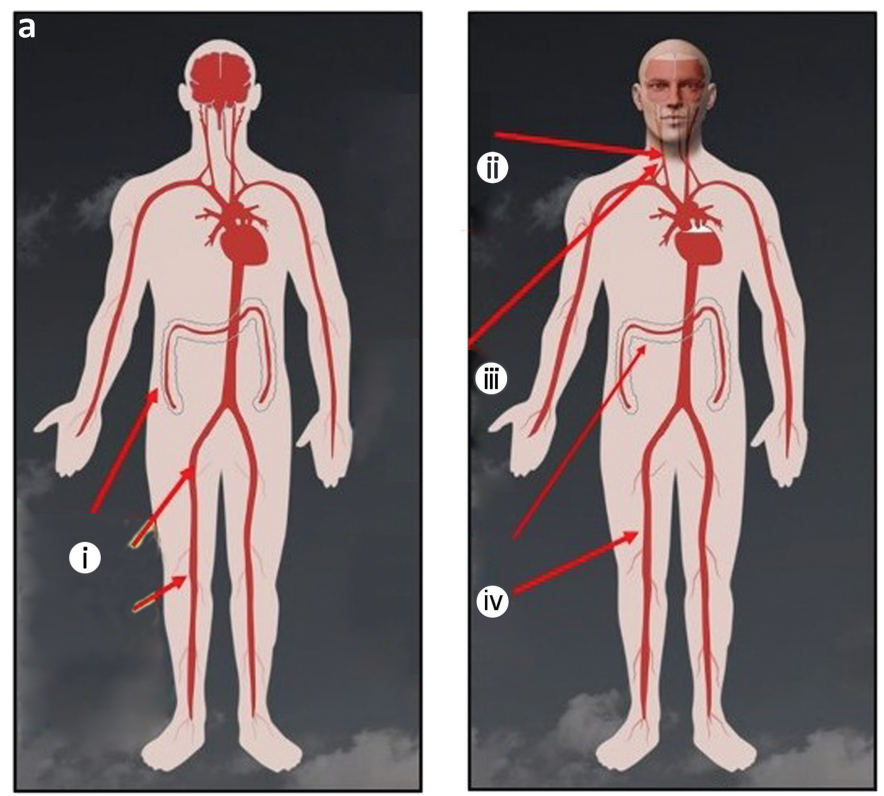

b

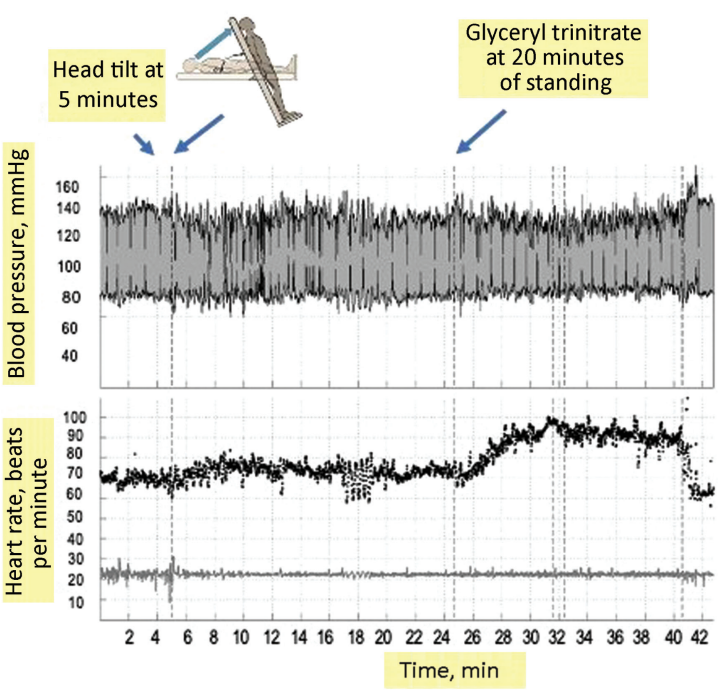

Fig 1. Normal haemodynamic changes on standing. a) i) Upon standing, blood pools in the legs, pelvis and gut, resulting in reduced venous return to the heart. ii) Baroreceptors in the aorta and carotid sinus, and mechanoceptors in the lungs and heart detect reduced venous return to the heart. iii and iv) Sympathetic nervous system activation releases noradrenaline into plasma with splanchnic/lower-limb vasoconstriction. The body's physiological response to standing is known as 'orthostasis'. Adapted with permission from Stop Fainting (www.stopfainting.com). b) Tilt table test: the heart rate (HR) and blood pressure (BP) reflect the normal haemodynamic response to standing on a tilt table. HR/BP are relatively stable on transition from lying to standing. A mild transient fall in $\mathrm{BP}$ occurs on reaching upright position, with a transient compensatory $\mathrm{HR}$ rise of $\sim 15 \%$.

the reduced plasma volume, leading to vasopressin release which contributes to vasoconstriction and increases plasma volume..$^{10,12}$ In neurogenic $\mathrm{OH}$ (Fig 2), the baroreflex is impaired, and these compensatory mechanisms do not occur, most obviously with a lack of increase in heart rate. Hypotension ensues, with persistent reduction in cardiac output. Unless this is corrected by sitting or lying supine, cerebral hypoperfusion and syncope may ensue.

Neurogenic $\mathrm{OH}$ results from impairment at multiple levels of the autonomic nervous system: from the brain and spinal cord to the pre-and post-ganglionic sympathetic and parasympathetic nervous systems, down to the peripheral autonomic nerves. The commonest cause in older people is the group of neurodegenerative disorders known as the synucleinopathies. This group includes Parkinson's disease (PD), dementia with Lewy bodies (DLB), multi-system atrophy (MSA) and primary autonomic failure. In $\mathrm{PD}$ (which confers a relative risk of 7 for $\mathrm{OH}$ as the disease progresses) and DLB, the dorsal motor nucleus of vagus is most likely to be affected. ${ }^{13}$ Lesions of peripheral autonomic nerves can be caused by diabetes, HIV, amyloidosis, autoimmune and paraneoplastic processes. ${ }^{10,11,14} \mathrm{OH}$ is present in around a third of diabetic patients, particularly in individuals with other end organ damage (such as peripheral neuropathy) and is associated with higher mortality. ${ }^{15}$

\section{$\mathrm{OH}$ associations pertinent to older people}

\section{Age-related changes to the autonomic nervous system}

Changes in the ANS and baroreflex are associated with ageing. Baroreceptor sensitivity is reduced in older patients, possibly due to atherosclerosis. As a result, appropriate compensatory mechanisms on orthostasis may not occur. ${ }^{16,17}$ Additionally the heart rate component of the baroreflex and the sympathetic control of muscle activity may be impaired. ${ }^{18,19}$

\section{Bedrest and immobility}

Immobility and associated deconditioning are major causes of $\mathrm{OH}$. A vicious cycle can develop, where $\mathrm{OH}$ leads to further immobility. Physical activity levels decline significantly after 70 years, even in healthy people. ${ }^{20}$ Activity levels in older inpatients are very low, even with physiotherapy. ${ }^{21}$

The physiological effects of prolonged bed rest have been well studied, as head-down bedrest are used as a model for investigating the effects of chronic weightlessness in space travel. Prolonged bedrest decreases plasma volume and total body blood volume, impairs baroreflex adjustment, reduces cardiac output and stroke volume, and inhibits sympathetic nerve responses. ${ }^{22-25}$

\section{Drugs}

Drug-induced $\mathrm{OH}$ is the most common reason for presentation to $\mathrm{ED}$ with $\mathrm{OH}^{2}$ Being on multiple drugs confers a higher risk. ${ }^{26}$ Particular culprits are selective serotonin reuptake inhibitors with an odds ratio (OR) of 2.42 for developing $\mathrm{OH}$, selective noradrenaline reuptake inhibitors (OR 5.37), tricyclic antidepressants, calcium channel blockers (OR 1.79) and benzodiazepines. ${ }^{26-28}$ Excess alcohol use is also associated with an increased risk (OR 2.17) possibly due to autonomic neuropathy. ${ }^{27}$ 

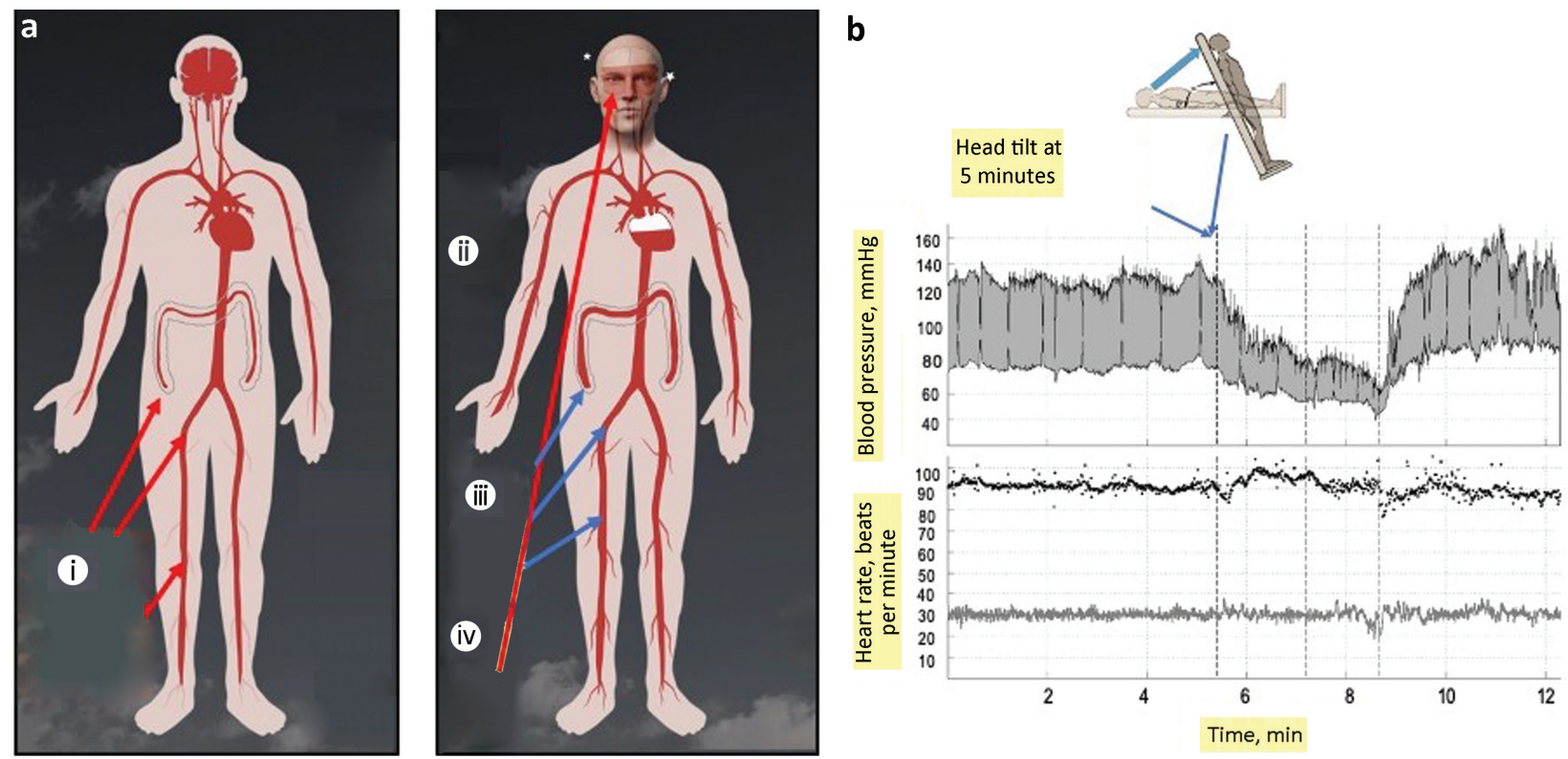

Fig 2. Haemodynamic changes occurring on standing in orthostatic hypotension. a) i) Upon standing, blood pools in the legs, pelvis and gut, resulting in reduced venous return to the heart. ii) Normal compensatory mechanisms for reduced venous return are absent. As a result, vasoconstriction does not occur and noradrenaline is not released into the circulation. iii) Blood continues to pool in the legs, pelvis and gut, leading to a further fall in venous return to the heart. iv) Brain hypoperfusion ensues and, unless the supine position is adopted, syncope occurs. Adapted with permission from Stop Fainting (www. stopfainting.com). b) Tilt table test: the heart rate and blood pressure reflect the physiological responses to standing on a tilt table. Following head-up tilt, the blood pressure falls until syncope is imminent at $>10$ minutes, at which point the supine position is resumed.

\section{Arterial stiffness}

Arterial stiffness, a biomarker of coronary artery disease and vascular ageing, positively correlates with $\mathrm{OH}$ independent of whether hypertension is present. ${ }^{29-31}$ Even in middle age, arterial stiffness correlates with an impaired autonomic response to standing. ${ }^{32}$ Additionally, individuals with atrial fibrillation are more likely to have $\mathrm{OH}$, likely due to higher burden of vascular pathology. ${ }^{33}$

\section{Frailty}

Frailty levels are positively correlated with $\mathrm{OH}$ and orthostatic intolerance symptoms, even without postural BP changes. ${ }^{34-38}$ Frailty also increases the risk of mortality, disability, functional decline and hospitalisation in individuals with $\mathrm{OH}^{39,40}$

\section{Delayed heart rate recovery on standing}

The Irish Longitudinal Study on Ageing (TILDA) has shown that failure to recover heart rate after standing when assessed by beat-to-beat monitoring is common and often asymptomatic. Nevertheless, it carries an adverse cardiovascular prognosis and is associated with $\mathrm{OH}$, falls and polypharmacy. ${ }^{41,42}$

\section{Cognitive impairment}

$\mathrm{OH}$ is associated with cognitive decline and dementia. ${ }^{43-47}$ One meta-analysis estimates an increased dementia risk of $21 \% .{ }^{43}$ In a memory clinic cohort, $\mathrm{OH}$ correlated with the severity of cognitive deficits, particularly executive function. ${ }^{44}$
Individuals with $\mathrm{OH}$ have increased white matter hyperintensity volume on magnetic resonance imaging (MRI) and faster cognitive deterioration rates. ${ }^{48}$ Additionally, the magnitude of $\mathrm{OH}$ correlates with white matter hyperintensity volume in depressed older people. ${ }^{49}$ This suggests altered haemodynamics and reduced cerebral perfusion. In patients with both mild cognitive impairment and Parkinson's disease, having $\mathrm{OH}$ increases the conversion risk to dementia. ${ }^{50,51}$ This could be caused by repetitive reduction in brain perfusion. Alternatively, it could reflect wider changes in the central and autonomic nervous systems in the synucleinopathies.

\section{Diagnosis}

The 'active stand test' involves measuring BP while supine, on standing and then after standing for 3 minutes. This may inform about immediate $\mathrm{OH}(\mathrm{OH}$ within 3 minutes) and classical $\mathrm{OH}(\mathrm{OH}$ at 3 minutes) but will not assess delayed $\mathrm{OH}$ (occurring after 3 minutes). Clinicians should be aware that patients with delayed $\mathrm{OH}$ may be unaware of their reduced cerebral perfusion and may present as falling, rather than dizziness or syncope.

Even more valuable is the active stand test with continuous electrocardiography (ECG) and beat-to-beat BP using a noninvasive photoplethysmographic device on the finger or wrist. This method will clearly show what happens to BP in the erect posture.

Other tests of value are notably the Valsalva manoeuvre which stresses the autonomic nervous system which, in neurogenic $\mathrm{OH}$, indicates the lack of heart rate rise that should occur. Twenty-fourhour ambulatory BP monitoring is also valuable in assessing the 
severity of the problem and detecting supine hypertension and post-prandial hypotension (for example, revealing blood pressure drops following mealtimes). Details of performance of these tests are available in the European Society of Cardiology (ESC) guidelines as an online supplement. ${ }^{52}$

\section{Management of orthostatic hypotension}

\section{General principles}

The aim of management is to reduce symptoms and improving standing time, physical function and activity. This takes precedence over optimising standing BP. ${ }^{53}$ An essential facet is patient education. Patients should be advised on hydration and diet, and to avoid triggers such as hot environments. ${ }^{1,53}$ Large carbohydrate-rich meals should be avoided because post-prandial hypotension can exacerbate symptoms. ${ }^{1} \mathrm{~A}$ medication review should occur with beta-blockers, thiazides, nitrates neuroleptics and dopaminergic agents under particular consideration. ${ }^{53,54}$ Individualised physical exercise regimens to combat deconditioning should be encouraged. ${ }^{1,53}$ Some consensus guidelines suggest avoiding orthostatic exercises and opting for horizontal exercise such as rowing machines, swimming and exercise bikes. ${ }^{53}$

During general assessment, anaemia, thyroid disorders, and vitamin D and B12 deficiencies should be corrected as these can contribute to and exacerbate $\mathrm{OH}^{53,55}$

Patients should be advised to measure their blood pressure at home and keep a diary detailing activities, fluid and salt intake, blood pressure readings and symptoms.

A summary of management is shown in Table 1.

\section{Non-pharmacological measures}

\section{Expand plasma volume: aim for fluid repletion}

Drinking water is an easy and effective way to improve BP. ${ }^{56}$ However, lack of thirst in this age group should be considered.

Mechanisms can be independent of the fluid itself and are due to increased sympathetic activity resulting in a pressor effect. ${ }^{57}$

The European Federation of Neurological Sciences (EFNS; now the European Academy of Neurology) suggests aiming for fluid repletion by drinking $2-2.5 \mathrm{~L}$ of fluid per day, and $500 \mathrm{~mL}$ bolus drinks when immediate rises in blood pressure are needed. ${ }^{1,58}$ This may be undesirable for people with continence and mobility issues. Additionally, a fine balance needs to be considered for those limited by fluid restrictions (such as those with heart failure and chronic kidney disease).

\section{Avoid venous pooling: teach physical manoeuvres}

Leg exercises (such as squatting, knee and leg crossing) are effective at reducing lower body pooling and expelling blood upwards towards the heart, increasing venous return and improving BP. ${ }^{12}$ Caution should be applied in individuals with balance problems. Patients should be shown how to employ these measures at symptom onset (Fig 3).,12

\section{Avoid venous pooling: compression garments}

Compressing the venous beds in the abdomen and legs is also effective. Evidence is strongest for abdominal compression. ${ }^{59-61}$

Table 1. Implications for practice: summary of the

key principles of managing orthostatic hypotension and neurogenic supine hypertension

Principle of management Intervention

General principles of management

Educate on avoiding triggers and encouraging self-management, such as patient diaries.

Review medications.

Treat anaemia, B12 deficiency, optimise causes of autonomic neuropathy (HIV/amyloidosis/ diabetes).

Non-pharmacological measures

\section{Pharmacological} measures

\section{Managing $\mathrm{OH}$ and $\mathrm{nSH}$}

Stockings should go as high as the waist to include abdominal compression. ${ }^{62}$ Stockings lower than waist height are not effective. ${ }^{53}$ Garments can be difficult to put on, and are not readily tolerated by many patients leading to variable compliance. Additionally, they are contraindicated in peripheral vascular disease, and require Ankle Brachial Pressure Index measurements prior to use.

\section{Expand plasma volume: supplement dietary salt}

Salt supplementation in patients with unexplained syncope significantly improves BP, orthostatic tolerance and baroreceptor sensitivity. ${ }^{63,64}$

Consensus guidelines suggest salt supplementation, with recommendations ranging from 4-10 g per day to $8 \mathrm{~g}$ day, the latter by the ESC.1,53,54 Salt repletion can be confirmed by a urinary sodium excretion of over $100 \mathrm{mEq} / 24$ hours. $^{53}$

Decrease venous return to inhibit natriuresis: head-up sleeping

Head-up sleeping improves orthostatic hypotension and symptoms both alone and in combination with drugs. ${ }^{65-67}$ This position 

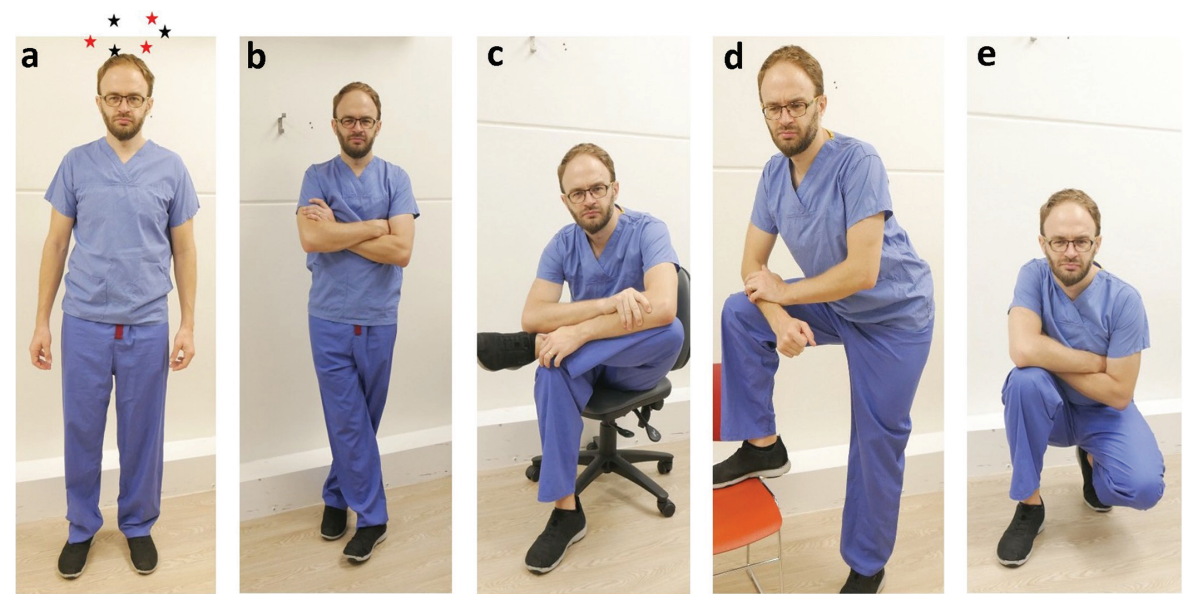

Fig 3. Physical counter-pressure manoeuvres. Patients should be educated on different physical counterpressure manoeuvres to employ at the onset of symptoms on standing (a). Tensing lower body muscles while crossing arms and legs ( $b$ and $c$ ), raising a leg onto a raised surface $(d)$ and squatting (e) can all increase venous return to the heart and raise blood pressure. maintains renin-angiotensin activation (maintaining plasma volume for the morning) and also avoid pressure natriuresis and hypovolaemia associated with supine hypertension.

Expert guidelines suggest elevating the head of the bed by $15-23 \mathrm{~cm}$ higher than the foot of the bed. ${ }^{53}$ Where possible, sleeping with the whole bed tilted (for example inpatient hospital beds) can also reduce nocturnal hypertension by pooling blood in the lower half of the body at night. ${ }^{68}$

Non-pharmacological measures can often be sufficient but, when they are not, medications can be considered. There are no head-to-head trials on which agents to use initially, but each case should be considered individually.

\section{Pharmacological measures}

\section{Volume expanders}

Fludrocortisone is a volume expander that works by increasing sodium and water absorption. It has been shown to benefit patients with $\mathrm{OH}^{69,70}$ However, data suggesting a benefit are weak. It is not well tolerated in older people and discontinuation is common, usually after around 8 months. ${ }^{71,72}$ The main problem is that the effects are not long-lasting, and supine hypertension develops early. ${ }^{73}$ Fludrocortisone is associated with hospitalisation in patients with heart failure. ${ }^{74}$ It should be avoided in cases of supine hypertension.

\section{Sympathomimetics}

Midodrine is an alpha-1 adrenoceptor agonist which increases BP by vasoconstriction. ${ }^{1}$ It improves orthostatic tolerance and quality of life in $\mathrm{OH}$ and reflex syncope. ${ }^{75-81}$ Side effects are supine hypertension, urinary retention and scalp itch due to pilomotor sensitivity. ${ }^{79}$ It should be avoided in older males with prostatic symptoms. However, randomised control trials have shown that it is well tolerated and these side effects do not generally stop treatment. $^{76,81}$

There is a significant risk of supine hypertension, so patients should be advised to avoid the supine position, avoid night-time doses and sleep head upright. ${ }^{53}$ Combining midodrine with an abdominal binder can result in greater improvement than midodrine alone. ${ }^{82}$
Consensus guidelines also recommend midodrine as monotherapy or combined therapy, avoiding night-time doses. Midodrine is short acting and, thus, should not exacerbate supine hypertension. It is contraindicated in severe heart disease, acute renal failure, phaeochromocytoma and thyrotoxicosis. ${ }^{1,53}$

\section{Other medications, not yet endorsed in guidelines}

Droxidopa is a noradrenaline prodrug which significantly improves $\mathrm{OH}$ and quality of life, and significantly reduces falls. ${ }^{53,83-85}$ Unlike midodrine, it does not cause increased supine hypertension, but it should also be avoided at night. It is not currently not endorsed by the ESC due to insufficient evidence in 2018..$^{54}$

Pyridostigmine is a cholinesterase inhibitor which increases cholinergic transmission in sympathetic ganglia, increasing sympathetic response to standing upright. It requires some residual autonomic function and is associated with cholinergic side effects, but does not result in supine hypertension. ${ }^{53}$

Octreotide is an analogue of somatostatin which inhibits vasodilatory gastrointestinal hormone release and plays a role in post-prandial hypotension. ${ }^{1}$ Desmopressin can be considered in nocturnal polyuria, and erythropoietin can be used in anaemia. ${ }^{54}$ Finally, atomoxetine is as effective as midodrine in neurogenic $\mathrm{OH}$ in improving BP and has been shown to be superior in improving orthostatic intolerance symptoms. ${ }^{86}$ It is not yet included in treatment guidelines.

\section{An age-old paradox: orthostatic hypotension and supine hypertension}

Counter-intuitively, orthostatic hypotension and concomitant nocturnal (or neurogenic) supine hypertension $(\mathrm{nSH})$ are very common: half of individuals with neurogenic $\mathrm{OH}$ will also have $\mathrm{nSH} .{ }^{68} \mathrm{nSH}$ is defined as BP greater than or equal to $140 / 90$ $\mathrm{mmHg}$ after 5 minutes in the supine position. ${ }^{68}$ This may manifest as 'reverse dipping' (the severe form with nSH) or 'non-dipping' (the loss of normal physiological nocturnal dip in BP). ${ }^{14}$ Both are caused by the same underlying issues: baroreflex and sympathetic nervous system activation are impaired, and the renin-angiotensin-aldosterone pathway is altered. In nSH, increased supine venous return at night induces a pressure diuresis, 
which can reduce circulating volume by up to $2 \mathrm{~kg}^{58}$ This then aggravates $\mathrm{OH}$ in the morning, worsening daytime symptoms. ${ }^{68}$

This paradox leads to significant treatment dilemmas. Both require treatment, but treating each risks exacerbating the other. $\mathrm{OH}$ is associated with risks of falls and injuries, but untreated hypertension leads to cardiovascular and renal disease. Calculating risk scores (such as FRAX for fragility fracture) and avoiding the highest risk situation should guide decision making.

There is little evidence in this area, but multiple consensus documents are available that suggest assessing and balancing risks and benefits. ${ }^{53,58,87}$ Consensus opinions suggest individualised intervention when systolic BPs reach 160-180 mmHg. In people with very high falls risk and severe postural BP drops, higher BPs should be permitted. ${ }^{53}$

All consensus statements recommend practical conservative measures. The driving principles are to reduce venous return to the heart at night, avoiding pressure diuresis and resulting morning hypovolaemia. Caution should be taken in treating supine hypertension in individuals who wake up at night for micturition, as this may significantly increase risk of nocturnal falls.

> Avoid the supine position, and sleep with the head of the bed raised by at least 10 degrees or by $25 \mathrm{~cm}$.

$>$ Avoid fludrocortisone (due to long half-life), diuretics and longacting hypertensives.

$>$ Limit water intake at night to avoid natriuresis.

> Consider a low-dose, short-acting antihypertensive to ameliorate nocturnal hypertension. ${ }^{58}$ Possible agents include a nitroglycerin patch, sildenafil, losartan, nebivolol, hydralazine, clonidine and nifedipine. ${ }^{53,58}$

> Have a snack before bedtime to induce post-prandial hypotension and reduce venous return to the heart.

$>$ Ideally, pressor agents (at lowest doses) should be used when needed rather than regularly to aid symptoms. ${ }^{14}$

\section{Monitoring and follow-up}

Identifying 'successful' treatment involves assessing symptoms, falls, quality of life, side effects and BP changes. If one medication is tried without symptomatic benefit or has intolerable side effects, it should be replaced with another and re-reviewed. Drug doses should be titrated to lowest effective dose and reviewed regularly. Adhering to conservative measures is emphasised. ${ }^{53}$

\section{Conclusion}

Orthostatic hypotension is a common, persistent and disabling condition which is encountered daily in general medical practice. It drastically impairs quality of life and results in rapid and progressive deconditioning and functional deterioration, often resulting in institutionalisation. When $\mathrm{OH}$ co-exists with supine hypertension, careful consideration of short- and medium-term risks should be balanced and discussed with the patient. Using simple, effective, practical measures to diagnose, monitor and alleviate it can have a major impact in maintaining independence in older people.

\section{References}

1 Lahrmann H, Cortelli P, Hilz M et al. EFNS guidelines on the diagnosis and management of orthostatic hypotension. Eur J Neurol 2006;13:930-6.
2 Sarasin FP, Louis-Simonet M, Carballo D et al. Prevalence of orthostatic hypotension among patients presenting with syncope in the ED. Am J Emerg Med 2002;20:497-501.

3 Aung AK, Corcoran SJ, Nagalingam V, Paul E, Newnham HH. Prevalence, associations, and risk factors for orthostatic hypotension in medical, surgical, and trauma inpatients: an observational cohort study. The Ochsner Journal 2012;12:35-41.

4 Duggan E, Romero-Ortuno R, Kenny RA. Admissions for orthostatic hypotension: an analysis of NHS England Hospital Episode Statistics data. BMJ Open 2019;9:e034087.

5 Ricci F, Fedorowski A, Radico F et al. Cardiovascular morbidity and mortality related to orthostatic hypotension: a meta-analysis of prospective observational studies. Eur Heart J 2015;36:1609-17.

6 Fleg JL, Evans GW, Margolis KL et al. Orthostatic hypotension in the ACCORD (Action to Control Cardiovascular Risk in Diabetes) blood pressure trial: prevalence, incidence, and prognostic significance. Hypertension 2016;68:888-95.

7 Min M, Shi T, Sun C et al. Orthostatic hypotension and the risk of atrial fibrillation and other cardiovascular diseases: An updated meta-analysis of prospective cohort studies. J Clin Hypertens (Greenwich) 2019;21:1221-7.

8 Juraschek SP, Daya N, Appel LJ et al. Orthostatic hypotension in middle-age and risk of falls. Am J Hypertens 2017;30:188-95.

9 Frithm Bashir AS, Newton JL. The duration of the orthostatic blood pressure drop is predictive of death. QJM 2016;109:231-5.

10 Freeman R, Abuzinadah AR, Gibbons $C$ et al. Orthostatic hypotension: JACC state-of-the-art review. J Am Coll Cardiol 2018;72: 1294-309.

11 Freeman R. Neurogenic orthostatic hypotension. N Engl ] Med 2008;358:615-24.

12 Smit AA, Halliwill JR, Low PA, Wieling W. Pathophysiological basis of orthostatic hypotension in autonomic failure. J Physiol 1999;519:1-10.

13 Hiorth YH, Pedersen KF, Dalen I, Tysnes OB, Alves G. Orthostatic hypotension in Parkinson disease: a 7-year prospective populationbased study. Neurology 2019;93:e1526-34.

14 Espay AJ, LeWitt PA, Hauser RA et al. Neurogenic orthostatic hypotension and supine hypertension in Parkinson's disease and related synucleinopathies: prioritisation of treatment targets. Lancet Neurol 2016;15:954-66.

15 Gaspar L, Kruzliak P, Komornikova A et al. Orthostatic hypotension in diabetic patients-10-year follow-up study. J Diabetes Complications 2016;30:67-71.

16 Callegaro CC, Taylor JA. Age-related effects of vagotonic atropine on cardiovagal baroreflex gain. Neurobiol Aging 2012;33:368-74.

17 Vlachakis ND, Mendlowitz M, DeGusman DD. Diminished baroreceptor sensitivity in elderly hypertensives: possible role of atherosclerosis. Atherosclerosis 1976;24:243-9.

18 McGarry K, Laher M, Fitzgerald D, Horgan J, O'Brien E, O'Malley K. Baroreflex function in elderly hypertensives. Hypertension 1983;5:763-6.

19 Matsukawa T, Sugiyama Y, Watanabe T, Kobayashi F, Mano T. Baroreflex control of muscle sympathetic nerve activity is attenuated in the elderly. Journal of the Autonomic Nervous System 1998:73:182-5.

20 McPhee JS, French DP, Jackson D et al. Physical activity in older age: perspectives for healthy ageing and frailty. Biogerontology 2016;17:567-80.

21 Lim SER, Dodds R, Bacon D, Sayer AA, Roberts HC. Physical activity among hospitalised older people: insights from upper and lower limb accelerometry. Aging Clin Exp Res 2018;30:1363-9.

22 Barbic F, Heusser K, Minonzio M et al. Effects of prolonged head-down bed rest on cardiac and vascular baroreceptor modulation and orthostatic tolerance in healthy individuals. Front Physiol 2019;10:1061.

23 Beck L, Baisch F, Gaffney FA et al. Cardiovascular response to lower body negative pressure before, during and after ten days head-down tilt bedrest. Acta Physiol Scand Supp/ 1992;604:43-52. 
24 Goldstein DS, Vernikos J, Holmes C, Convertino VA. Catecholaminergic effects of prolonged head-down bed rest. J Appl Physiol 1985;78: 1023-9.

25 Kamiya A, MIchikami D, Fu Q et al. Pathophysiology of orthostatic hypotension after bed rest: paradoxical sympathetic withdrawal. Am J Physiol Heart Circ Physiol 2003;285:H1158-67.

26 Press Y, Punchik B, Freud T. Orthostatic hypotension and drug therapy in patients at an outpatient comprehensive geriatric assessment unit. J Hypertens 2016;34:351-8.

27 Gaxatte C, Faraj E, Lathuillerie $O$ et al. Alcohol and psychotropic drugs: risk factors for orthostatic hypotension in elderly fallers. J Hum Hypertens 2017;31:299-304.

28 Rivasi G, Kenny RA, Ungar A, Romero-Ortuno R. Effects of benzodiazepines on orthostaitc blood pressure in older people. Eur ] Intern Med 2020;72:73-8.

29 Cremer A, Boutouyrie P, Laurent S, Gosse P, Tzourio C. Orthostatic hypotension: a marker of blood pressure variability and arterial stiffness: a cross-sectional study on an elderly population: the 3-City study. J Hypertens 2020;38:1103-9.

30 Mattace-Raso FU, van der Cammen TJ, Knetsch AM et al. Arterial stiffness as the candidate underlying mechanism forpostural blood pressure changes and orthostatic hypotension in older adults: the Rotterdam Study. J Hypertens 2006;24:339-44.

31 Boddaert J, Tamim H, verny M, Belmin J. Arterial stiffness is associated with orthostatic hypotension in elderly subjects with history of falls. JAGS 2004;52:568-72.

32 Torjesen A, Cooper LL, Rong ] et al. Relations of arterial stiffness with postural change in mean arterial pressure in middle-aged adults: the Framingham heart study. Hypertension 2017;69:685-90.

33 McNicholas T, Tobin K, O'Callaghan S, Kenny RA. Is orthostatic hypotension more common in individuals with atrial fibrillation?Findings from The Irish Longitudinal Study on Ageing (TILDA). Age Ageing 2017:46:1006-10.

34 O'Connell MD, Savva GM, Fan CW, Kenny RA. Orthostatic hypotension, orthostatic intolerance and frailty: The Irish Longitudinal Study on Aging-TILDA. Arch Gerontol Geriatr 2015:60:507-13.

35 van Twist DJL, Mostard GJM, Sipers W. Delayed recovery from initial orthostatic hypotension: an expression of frailty in the elderly. Clin Auton Res 2020.

36 Rockwood MR, Howlett SE, Rockwood K. Orthostatic hypotension $(\mathrm{OH})$ and mortality in relation to age, blood pressure and frailty. Arch Gerontol Geriatr 2012;54:e255-60.

37 Kocyigit SE, Soysal P, Bulut EA et al. What is the relationship between frailty and orthostatic hypotension in older adults? J Geriatr Cardiol 2019;16:272-9.

38 Chen LY, Xu Y, Chen XJ, Lee W], Chen LK. Association between orthostatic hypotension and frailty in hospitalised older patients: a geriatric syndrome more than a cardiovascular condition. J Nutr Health Aging 2019;23:318-22.

39 Liguori I, Russo G, Coscia V et al. Orthostatic hypotension in the elderly: a marker of clinical frailty? J Am Med Dir Assoc 2018:19:779-85.

40 Jodaitis L, Vaillant F, Snacken M et al. Orthostatic hypotension and associated conditions in geriatric inpatients. Acta Clin Belg 2015;70:251-8.

41 McCrory C, Berkman L, Nolan $\mathrm{H}$ et al. Speed of heart rate recovery in response to orthostatic challenge: a strong risk marker of mortality. Circ Res 2016;119:666-75.

42 Moloney D, O'Connor J, Newman L et al. Clinical clustering of eight orthostatic haemodynamic patterns in The Irish Longitudinal Study on Ageing (TILDA). Age Ageing 2020;afaa174.

43 Peters R, Anstey KJ, Booth A et al. Orthostatic hypotension and symptomatic subclinical orthostatic hypotension increase risk of cognitive impairment: an integrated evidence review and analysis of a large older adult hypertensive cohort. Eur Heart ] 2018;39:3135-43.
44 Bocti C, Pepin F, Tetreault M et al. Orthostatic hypotension associated with executive dysfunction in mild cognitive impairment. J Neurol Sci 2017;382:79-83.

45 Huang $\mathrm{H}$, Zheng $\mathrm{T}$, Liu $\mathrm{F}$ et al. Orthostatic hypotension predicts cognitive impairment in the elderly: findings from a cohort study. Front Neurol 2017:8:121.

46 Iseli R, Nguyen VTV, Sharmin S et al. Orthostatic hypotension and cognition in older adults: A systematic review and meta-analysis. Exp Gerontol 2019;120:40-9.

47 McNicholas T, Tobin K, Carey D, O'Callaghan S, Kenny RA. Is baseline orthostatic hypotension associated with a decline in global cognitive performance at 4-year follow-up? Data from TILDA (The Irish Longitudinal Study on Ageing). J Am Heart Assoc 2018:7:e008976.

48 Timmermans ST, Reijnierse EM, Pasma JH et al. Blood pressure change does not associate with center of pressure movement after postural transition in geriatric outpatients. BMC Geriatr 2018;18:10.

49 Colloby S], Vasudev A, O'Brien JT et al. Relationship of orthostatic blood pressure to white matter hyperintensities and subcortical volumes in late-life depression. Br J Psychiatry 2011;199: 404-10.

50 Sorond FA, Khavari R, Serrador JM, Lipsitz LA. Regional cerebral autoregulation during orthostatic stress: age related differences. J Gerontol A Biol Sci Med Sci 2005;60:1484-7.

51 Anang JB, Gagnon JF, Bertrand JA et al. Predictors of dementia in Parkinson disease: a prospective cohort study. Neurology 2014;83:1253-60.

52 Brignole M, Moya A, De Langhe F] et al. Practical Instructions for the 2018 ESC Guidelines for the diagnosis and management of syncope. Eur Heart J 2018;39:e43-80.

53 Gibbons $\mathrm{CH}$, Schmidt P, Biaggioni I et al. The recommendations of a consensus panel for the screening, diagnosis, and treatment of neurogenic orthostatic hypotension and associated supine hypertension. J Neurol 2017;264:1567-82.

54 Brignole M, Moya A, de Lange FJ et al. 2018 ESC Guidelines for the diagnosis and management of syncope. Eur Heart J 2018;39:1883-948.

55 Ometto F, Stubbs B, Annweiler C et al. Hypovitaminosis D and orthostatic hypotension: a systematic review and meta-analysis. J Hypertens 2016;34:1036-43.

56 Jordan J, Shannon JR, Black BK et al. The pressor response to water drinking in humans: a sympathetic reflex? Circulation 2000;101:504-9.

57 Young TM, Mathias C]. The effects of water ingestion on orthostatic hypotension in two groups of chronic autonomic failure: multiple system atrophy and pure autonomic failure. J Neurol Neurosurg Psychiatry 2004;75:1737-41.

58 Jordan J, Fanciulli A, Tank J et al. Management of supine hypertension in patients with neurogenic orthostatic hypotension: scientific statement of the American Autonomic Society, European Federation of Autonomic Societies, and the European Society of Hypertension. J Hypertens 2019;37:1541-6.

59 Deng JC, Opfer-Gerhking TL, Giuliani M et al. Efficacy of compression of different capacitance beds in the amelioration of orthostatic hypotension. Clin Auton Res 1997;7:321-6.

60 Smit AA, Wieling W, Fujimura ] et al. Use of lower abdominal compressino to combat orthostatic hypotension in patients with autonomic dysfunction. Clin Auton Res 2004;14:167-75.

61 Subbarayan S, Myint PK, Martin KR et al. Nonpharmacologic management of orthostatic hypotension in older people: a systematic review. The SENATOR ONTOP series. J Am Med Dir Assoc 2019;20:1065-73.e3.

62 Tanaka K, Tokumiya S, Ishihara Y, Kohira Y, Katafuchi T. Compression stocking length effects on arterial blood pressure and heart rate following head-up tilt in healthy volunteers. Nurs Res 2014;63:435-8. 
63 Cooper VL, Hainsworth R. Effects of dietary salt on orthostatic tolerance, blood pressure and baroreceptor sensibility in patients with syncope. Clin Auton Res 2002;12:236-41.

64 El-Sayed H, Hainsworth R. Salt supplement increases plasma volume and orthostatic intolerance in patiehts with unexplained syncope. Heart 1996;75:134-40.

65 Cooper VL, Hainsworth R. Head-up sleeping improves orthostatic tolerance in patients with syncope. Clin Auton Res 2008;18:318-24.

66 van Lieshout J], ten Harkel AD, Wieling W. Fludrocortisone and sleeping in the head-up position limit the postural decrease in cardiac output. Clin Auton Res 2000;10:35-42.

67 ten Harkel AD, van Lieshout J], Wieling W. Treatment of orthostatic hypotension with sleeping in the head-up tilt position, alone and in combination with fludrocortisone. J Intern Med 1992;232:139-45.

68 Fanciulli A, Jordan J, Biaggioni I et al. Consensus statement on the definition of neurogenic supine hypertension in cardiovascular autonomic failure by the American Autonomic Society (AAS) and the European Federation of Autonomic Societies (EFAS): Endorsed by the European Academy of Neurology (EAN) and the European Society of Hypertension (ESH). Clin Auton Res 2018;28:355-62.

69 Ong HL, Abdin E, Seow E et al. Prevalence and associative factors of orthostatic hypotension in older adults: Results from the Wellbeing of the Singapore Elderly (WiSE) study. Arch Gerontol Geriatr 2017;72:146-52

70 Campbell IW, Ewing DJ, Clarke BF. 9-alpha-fluorohydrocortisone in the treatment of postural hypotension in diabetic autonomic neuropathy. Diabetes 1975;24:381-4.

71 Hussain RM, McIntosh S], Lawson J, Kenny RA. Fludrocortisone in the treatment of hypotensive disorders in the elderly. Heart 1996;76:507-9.

72 Shibao C, Grijalva CG, Lipsitz LA, Biaggioni I, Griffin MR. Early discontinuation of treatment in patients with orthostatic hypotension. Auton Neurosci 2013;177:291-6.

73 Chobanian AV, Volicer L, Tifft CP, Gavras H, Liang C-S, Faxon D. Mineralocorticoid-induced hypertension in patients with orthostatic hypotension. N Engl J Med 1979;301:68-73.

74 Grijalva CG, Biaggioni I, Griffin MR, Shibao CA. Fludrocortisone is associated with a higher risk of all-cause hospitalizations compared with midodrine in patients with orthostatic hypotension. J Am Heart Assoc 2017;6:e006848.

75 Izcovich A, Gonzalez Malla C, Manzotti M, Catalano H, Guyatt G. Midodrine for orthostaticv hypotensino and recurrent reflex syncope. Neurology 2014;83:1170-7.

76 Jankovic J, Gilden JL, Hiner BC et al. Neurogenic orthostatic hypotension: a double-blind, placebo-controlled study with midodrine. Am J Med 1993:95:38-48.
77 Wright RA, Kaufmann HC, Perera R et al. A double-blind, doseresponse study of midodrine in neurogenic orthostatic hypotension. Neurology 1998;51:120-4.

78 Byun JI, Moon J, Kim DY et al. Efficacy of single or combined midodrine and pyridostigmine in orthostatic hypotension. Neurology 2017:89:1078-86.

79 Low PA, Gilden JK, Freeman R, Sheng KN, McElligott MA. Efficacy of midodrine vs placebo in neurogenic orthostatic hypotension. A randomised, double blind multicenter study. Midodrine Study Group. JAMA 1997:277:1046-51.

80 Ong AC, Myint PK, Shepstone L, Potter JF. A systematic review of the pharmacological management of orthostatic hypotension. Int J Clin Pract 2013;67:633-46.

81 Smith WM, Wan H, Much D, Robinson AG, Martin P. Clinical benefit of midodrine hydrocholoride in symptomatic orthostatic hypotension: a phase 4, double-blind, palacebo-controlled, randomised, tilt-table study. Clin Auton Res 2016;26:269-77.

82 Okamoto LE, Diedrich A, Baudenbacher FJ et al. Efficacy of servo-controlled splanchnic venous compression in the treatmet of orthostatic hypotension. A randomised comparison with midodrine. Hypertension 2016;68:418-26.

83 Hauser RA, Biaggioni I, Hewitt LA, Vernino S. Integrated analysis of droxidopa for the treatment of neurogenic orthostatic hypotension in patients with Parkinson disease. Movement Dis Clin Practice 2018:5:627-34.

84 Kaufmann H, Palma JA. Neurogenic orthostatic hypotension: the very basics. Clin Auton Res 2017;27:39-43.

85 Chen J], Han Y, Tang J et al. Standing and supine blood pressure outcomes associated with droxidopa and midodrine in patients with neurogenic orthostatic hypotension: a Bayesian metaanalysis and mixed treatment comparison of randomised trials. Ann Pharmacother 2018;52:1182-94.

86 Byun J-I, Kim D-Y, Moon J et al. Efficacy of atomoxetine versus midodrine for neurogenic orthostatic hypotension. Ann Clin Transl Neurol 2020;7:112-20.

87 Kearney F, Moore A. Treatment of combined hypertension and orthostatic hypotension in older adults: more questions than answers still remain. Expert Rev Cardiovasc Ther 2009;7:557-60.

Address for correspondence: Dr Melanie Dani, Imperial Syncope Unit, Hammersmith Hospital, Imperial College Healthcare NHS Trust, Du Cane Road, London W12 0HS, UK. Email: melanie.dani@nhs.net

Twitter: @drmelaniedani 